\title{
Cut-off Low Patterns and its simultaneous Precipitation over Iran
}

Ghasem Azizi, Professor, Department of Physical Geography, University of Tehran, Tehran, Iran. ghazizi@ut.ac.ir

https://orcid.org/0000-0002-9797-4834

Hossein Rezaei ${ }^{1}$, Assistant Professor, Central Tehran Branch, Islamic Azad University, Tehran, Iran. u.rezaei@gmail.com

https://orcid.org/0000-0001-7405-6806

\begin{abstract}
Iran located in arid and semiarid area of the earth with low precipitation. Iran's rainfall is mainly received in the cold period of the year. Although the total annual precipitation is low but sometime, the country receives heavy rainfall. One of the conditions that lead to heavy rainfall is cut-off low patterns. Cut-off low-pressure systems are defined as closed lows in the upper troposphere that have become completely detached from the main westerly current. The characteristics of Cut-off Lows in Iran are studied for the period of 1976-2015. To identify these systems, the Raul Nieto algorithm was used with automatic detection capabilities. The systematic identification of Cut-off Lows is realized by applying an original automated scheme using mean daily geopotential height, wind and air temperature at $500 \mathrm{hPa}$ NCEP. Cut-off Lows are more frequent during spring in the Iran, with a maximum of frequency in March. Over the period of 1976-2015, the annual Cut-off Lows frequency exhibits a weak positive trend. In this study, the most cut-off lows lasted only 2 days. Simultaneous precipitation with cut-off low pressures was compared with annual precipitation of stations. Northwest of Iran has a larger share of Cut-off low precipitation. Different Cut-off Low patterns were identified under 6 separate patterns. The highest frequency of cut-off lows are the eastern arm of omega pattern.
\end{abstract}

Keywords: Blocking high, Rex Pattern, COLs, rainfall.

\section{Declarations}

Theoretical and Applied Climatology

Jun 16, 2021

Dear Prof. Dr. Hartmut Graß1

I would like to submit the manuscript entitled "Cut-off Low Patterns and its simultaneous Precipitation over Iran" by Ghasem Azizi and Hossein Rezaei to be considered for publication as an original article in the Theoretical and Applied Climatology.

We declare that this manuscript is original, has not been published before and is not currently being considered for publication elsewhere. This manuscript is part of the results of the Ph.D. dissertation of the corresponding author, which has been defended at the University of Tehran under the supervision of the first author.

Funding: there has been no significant financial support for this work that could have influenced its outcome.

Conflicts of interest/Competing interests: We know of no conflicts of interest associated with this publication and we have no potential conflict of interest in relation to the study in this paper.

Availability of data and material: All data and material used in this article is available and could be provided.

Code availability: 'Not applicable'

As Corresponding Author, I confirm that the manuscript has been read and approved for submission by all the named authors.

We hope you find our manuscript suitable for publication and look forward to hearing from you in due course.

1 - Corresponding author: u.rezaei@gmail.com tel: +989122086951 
Sincerely,

Hossein Rezaei, Assistant Professor, Central Tehran Branch, Islamic Azad University, Tehran, Iran.

Email: u.rezaei@gmail.com- +989122086951

\section{Introduction}

Cut-off Lows (COLs) are hazardous atmospheric systems that have a significant impact on society because of their association with tempestuous weather. They are defined as mid and upper tropospheric cold lows, which generate and develop in the westerlies (Alice favre, 2012). COLs are upper-level low-pressure areas formed on the equatorward side of the maximum westerly winds in the polar or the subtropical jet stream (Fuenzalida. 2005). Cut-off lows are isolated cyclonic vortices that form as a result of meridional excursions of jet streams. They are synoptic-scale features, typically a thousand kilometers across (Price and Vaughan, 1992). Two mechanisms are possible for mixing the stratospheric air into the troposphere-isentropic filamentation of air away from the low followed by mixing outside it, or mixing across the tropopause within the low itself (either by convective penetration or clear-air turbulence) (Gouget, 2000). A cut-off low is an atmospheric phenomenon of mid and high latitudes that can have various impacts on the climate of regions under its influence. About $50 \%$ of the low-pressure area is usually covered by different types of clouds, with a higher percentage in the front area (Delgado and Lorente, 2007). In similar studies, which have investigated the impacts of cut-off lows in several regions of Australia, South Africa, Europe, quantitative and qualitative methods have been implemented for the identification of these systems.

According to a theory presented by Kleinschmidt (1950), cut-off low is formed due to permeation of stratospheric air potential vorticity in the polar region, to the upper troposphere. This theory was developed by Hoskin (1985), and showed that cut-off low is caused by an isolated pool of potential vorticity in the mid and upper troposphere, which has been accompanied by tropopause descent. Telgard (1985) studied the status of cutoff lows in South Africa for ten years and investigated their properties, prevalence and relation to precipitation. On average, he identified 11 cut-off lows every year, with the highest number in the spring and summer seasons. Parker et al. (1989) showed that the frequency trend of cut-off lows at 500-hPa level decreased from 1950 to 1970 and increased from 1971 to 1985. Similarly, Prize and Wagan (1992) and Kentarchos \& Davies (1998) developed a climatological analysis of cut-off lows in the northern hemisphere. These studies were generally carried out for a short-term period, such that Prize's study was conducted for a one-year period (October 1982 to September 1983). Kentarchos and Davies (1998) studied the climatology of cut-off lows at $200 \mathrm{hPa}$ in the Northern Hemisphere during a 5-years period (1990-1994). They explored every closed geopotential cyclonic curvature at a $200 \mathrm{hPa}$ pressure level. They concluded that all the COLs that lasted for 2 days or more have formed more often in summer than winter and in preferred geographical regions and about $50 \%$ of cut-off lows, which last longer than three days, travel a significant distance (more than $600 \mathrm{~km}$ ). Prize found that almost half these systems have considerable movement. Nieto et al. (2008) introduced the northern hemisphere, southwestern Europe, northeast of the pacific coast and northern China and the Siberian region as the main occurrence sites for cut-off lows. Reboita et al. (2010) examined the climatic properties of cut-off low systems in the southern hemisphere and showed that the highest frequency of them is at 300-hPa level, followed by 500 and 200 levels. They revealed that their seasonal distribution is also different at various levels and their frequency at these levels in summer; autumn and winter were higher than in spring. During these seasons, they are mostly situated around the continental areas such as the area between southeastern Australia and New Zealand, south of South America and south of Africa. Tando et al. (2010) investigated the link between cut-off low and Rossby wave breaking in the southern hemisphere. Amy Hodgson (2012) analyzed cut-off lows in northwestern Africa in April 2011 and analyzed heavy precipitation in Morocco with the localization time of these systems. Chuanxi et al. (2013) examined the dynamic and chemical properties of cut-off lows in northeastern China. They stated that tropospheric ozone analysis shows evidence of transmission and incorporation of stratospheric ozone rich air into the upper troposphere and in the frontal area of cut-off low center in this region. Oakley and Redmond (2014) studied the climatology of closed low altitudes in the northeast of the Pacific Ocean in the 1945-2011 period. These researchers showed that the event frequency of these systems in positive phases of ENSO is more than average. 
In this paper, the impacts of cut-off lows systems have been investigated on precipitation in Iran. Generally, short term and long-term periods have been studied through qualitative and quantitative methods, respectively. In this study, the quantitative method has been used to detect cut-off lows. After identification of these systems, cut-off lows affecting Iran were discriminated from cut-off lows that were identified in the studied region but traveled a path other than Iran. In this paper, in addition to cut-off low detection, the geographical position of formation sites and routes, as well as the precipitation effect of these systems on the selected stations have been studied. Finally, dominant patterns of these systems were identified and studied. Due to the particular importance of cut-off lows and their role in precipitation, and considering the fact that a comprehensive study on these systems has not been conducted in Iran, the present study attempts to fill this void by investigating them and answering questions regarding their effects on precipitation in Iran. As the initial steps, the detection and identification of these systems are critical

\section{3- 1 Data and method}

Data for a period of 40 years (1976 to 2015) were extracted from the National Center for Atmospheric Research with a resolution of 2.5 to 2.5 degrees for the latitude range of 10 to $60^{\circ} \mathrm{N}$ and longitude 0 to $80{ }^{\circ} \mathrm{E}$. In this study, cut-off lows were studied at the levels of 500 and $600 \mathrm{hPa}$. To identify cut-off lows, the method of Nieto et al. (Nieto et al., 2007) and Robita et al. (2010) were used. According to this method, to identify a cut-off low system, it is necessary to identify four features. To identify these features, an algorithm was written in MATLAB software to automatically detect cut-off lows systems by examining the conditions in the algorithm after receiving the data. The data used in this algorithm to identify cut-off lows are geopotential height at the levels of 500 and 600-hPa, thickness between these two levels, zonal wind (u) at the level of 500-hPa and finally temperature at the level of 500-hPa.

In the algorithm, the cut-off low must have four properties, which are as follows:

- Closed cyclonic circulation (closed cell): This step involves identifying the minimum height of the geopotential point at the desired level $(500 \mathrm{~mm})$. To do this, any point in the network whose geopotential height is less than at least six points (of 8 points) around them is selected. Then those points, whose geopotential height difference with the surrounding points is at least ten meters, are kept for the next step and the rest are removed from the algorithm.

- Isolation of the closed cell from the main zonal current (cutting): To do this, a change in the zonal wind direction should occur at the desired level. That is, at least one of the two points north of the adjacent point (minimum point of geopotential height) must have the opposite sign.

- Equivalent thickness: which is the thickness of the atmospheric layer between two pressure levels. At a cut-off low this characteristic is characterized by a greater thickness at the front of the low. Therefore, in the algorithm, the thickness equivalent to the east of the center point must be greater than the center point. For a layer of thickness $600-500 \mathrm{hPa}$, the difference between the values of the geopotential height of these two surfaces is calculated and the value of the point east of the center point should be greater than the center point.

- Temperature front parameter (TFP): which indicates temperature changes along the gradient line. In the algorithm, the value of TFP in the east of the center point should be higher than the value of TFP in the center point. Because the cut-off lows are characterized by an area with a high-pressure gradient in front of the cut-off low that is connected to a forward cloud band. The mathematical definition of TFP is as follows (Nieto et al., 2007):

$$
\mathrm{TFP}=-\nabla|\nabla \mathrm{T}| \cdot(\nabla \mathrm{T} /|\nabla \mathrm{T}|)
$$

The phrase of $-\nabla|\nabla \mathrm{T}|$ shows change of temperature gradient and the second part ( $\nabla \mathrm{T} /|| \mathrm{T} \mid)$ shows an increase or decrease in the sign of the temperature gradient. In this study, the seasons of the year are defined as follows: winter including December, January and February, spring including March, April and May, summer including June, July and August, autumn including September, October and November. Regarding the method of identifying cut-off lows affecting Iran, cut-off low must have at least one of the following conditions (Figure 1):

1- All or part of the cut-off low`s closed cells settled on a part of Iran.

2- Areas of Iran should be located in a radius of about $1000 \mathrm{~km}\left(10^{\circ}\right.$ longitude and latitude) from the cut-off low center.

For this step, manual survey of maps and GIS software were used. 


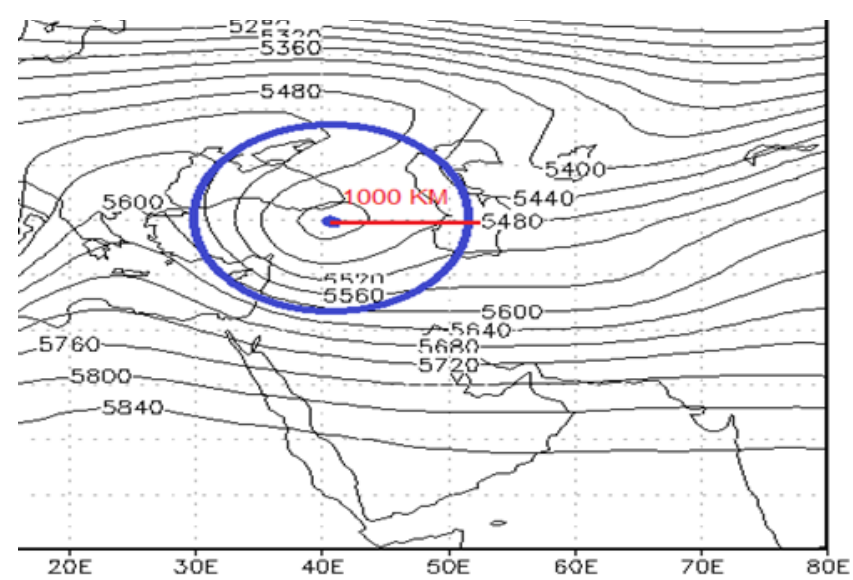

Figure 1: An example of a cut-off low that has affected Iran (January 15, 1980).

After identifying the cut-off low centers by the algorithm during the 40-year period and separating the effective and ineffective cut-off lows on Iran, the place of formation of each system and the frequency of their occurrence in different regions of Iran and in different seasons were identified. To analyze the precipitation associated with COLs, data of daily precipitation from the 23 stations were used. These daily precipitation data of the studied stations were acquired from Iran Meteorological Organization.

\section{3- 2 Results and discussion}

\section{3- 1 Area of formation}

Although cut-off lows located in the west and north of Europe cannot have any direct influence on precipitation in Iran, these regions could be the origin and birthplace of cut-off lows, which may also have a direct impact on Iran along their way. Nevertheless, regions outside of the selected area in this study are not even the origin and place of creation for systems affecting Iran.

The Geographical distribution of cut-off lows which coincided with the rainfall or affected the rainfall over Iran show that the generative zones affecting Iran are include a large areas, most of which are located east of the Mediterranean Sea and south of the Black Sea between $25^{\circ} \mathrm{E}-50^{\circ} \mathrm{E}$ and $32^{\circ} \mathrm{N}-38^{\circ} \mathrm{N}$. The detail can be seen in Figure 2, the generative zones affecting Iran are Greece, east, west and south of Turkey, center and east of the Black Sea, Caspian, and north of the Mediterranean Sea, Jordan, Syria, Iraq, Aral and Turkmenistan area.

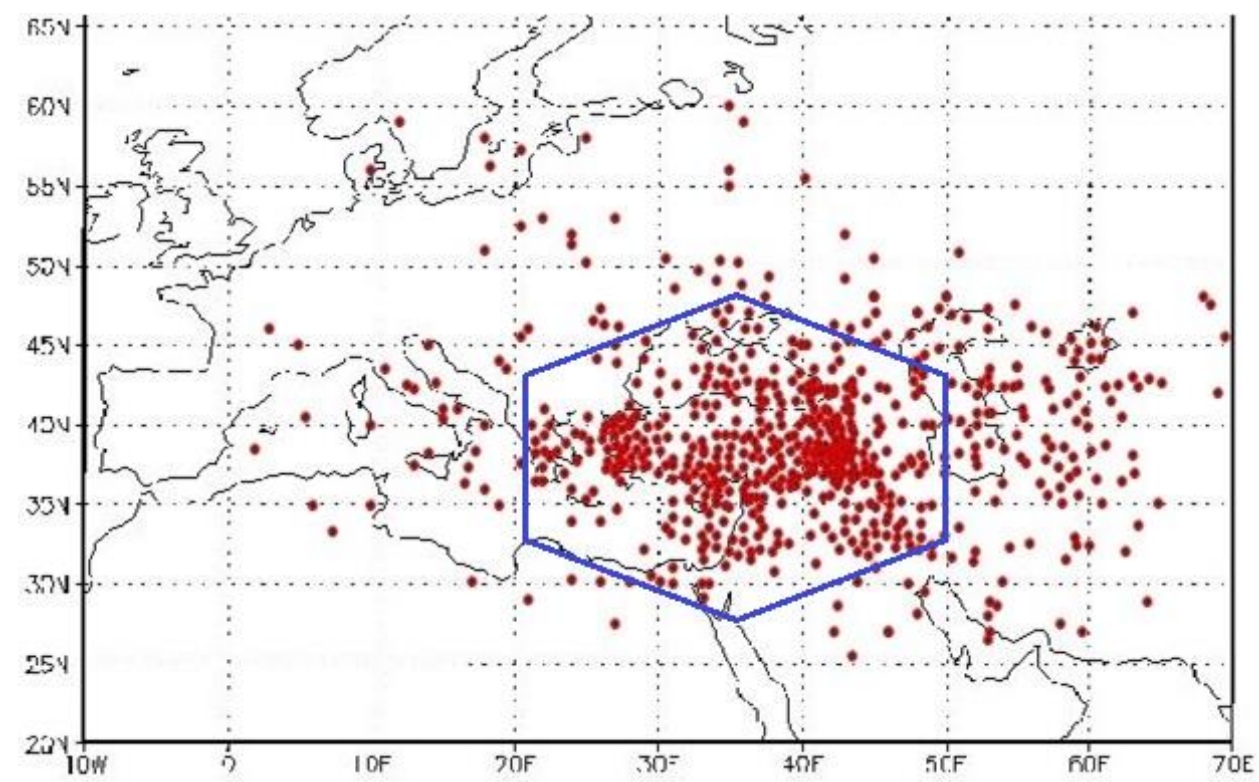

Figure 2. Geographical distribution of cut-off lows, which coincided with the rainfall or affected the rainfall over Iran. (The blue box shows that the most of them are located east of the Mediterranean Sea and south of the Black Sea). 
Due to cut-off low scales being synoptic and their considerable movement, it is expected that the area of appearance and genesis of these systems be mostly outside of Iran. Therefore, recognizing the area of genesis and the main travel route of these systems through Europe and the Middle East is of importance.

\section{3- 2 Temporal distribution}

\section{- Monthly and seasonal distribution}

In this study, Seasons are defined as winter (DJF), spring (MAM), summer (JJA) and fall (SON). During the forty-year statistical period, overall 628 cut-off lows affecting Iran with at least one-day persistency were identified. Their monthly frequency is shown in Figure 3. According to the figure, the month of March shows the highest frequency, with 93 events of cut-off lows during forty years. As can be seen, most frequencies occurred during the colder months. Due to the geographical location of Iran, it is possible for the western winds to spread over Iran in the cold period months. For this reason, the cut-offs are also more concentrated in this period. Regarding seasons, the months of spring with 240 cases had the highest cut-off low events, which is consistent with the definition of cut-off low system formation based on jet stream attenuation in spring. Studies show that seasonal changes of cut-off lows are associated with jet stream, such that cut-off lows have more tendency to appear when jet streams are weak (Ndarana and Wag, 2010). After spring, winter with 223 cases had the highest number of occurrence, due to the frequency of cut-off low systems and domination of western winds in this season. In autumn 124 cut-off low events were observed. In the earlier of autumn, these systems are still observed in higher latitudes, While until the end of the autumn season, by moving to lower latitudes, they are in a position that is more suitable for creating precipitation over Iran (September 13, October 46 and November 65 cases). due to latitudes covered Iran (15-40N), The lowest frequency of cut-off lows effected Iran occurred in summer which is the exact opposite of the European region and in general the higher latitudes of the northern hemisphere that the highest frequency of cut-off lows is in summer season. This despite the fact that the most cut-off low events in the mid and upper latitudes of the northern hemisphere occur during summer. The seasonal difference of these events in Iran compared to Europe and other regions located in higher latitudes is due to the constant presence of subtropical high pressure during the summer season in Iran, which does not grant entrance to these rainfall systems. Therefore, Iran does not benefit from summer-time cut-off lows, which have the highest frequency in the northern hemisphere.

Figure 4 shows the frequency percentage of cut-off lows during different seasons. Spring with $38.2 \%$ has the highest frequency. Winter with $35.5 \%$, autumn with $19.7 \%$, and finally summer with $6.5 \%$ frequency are in the next ranks.

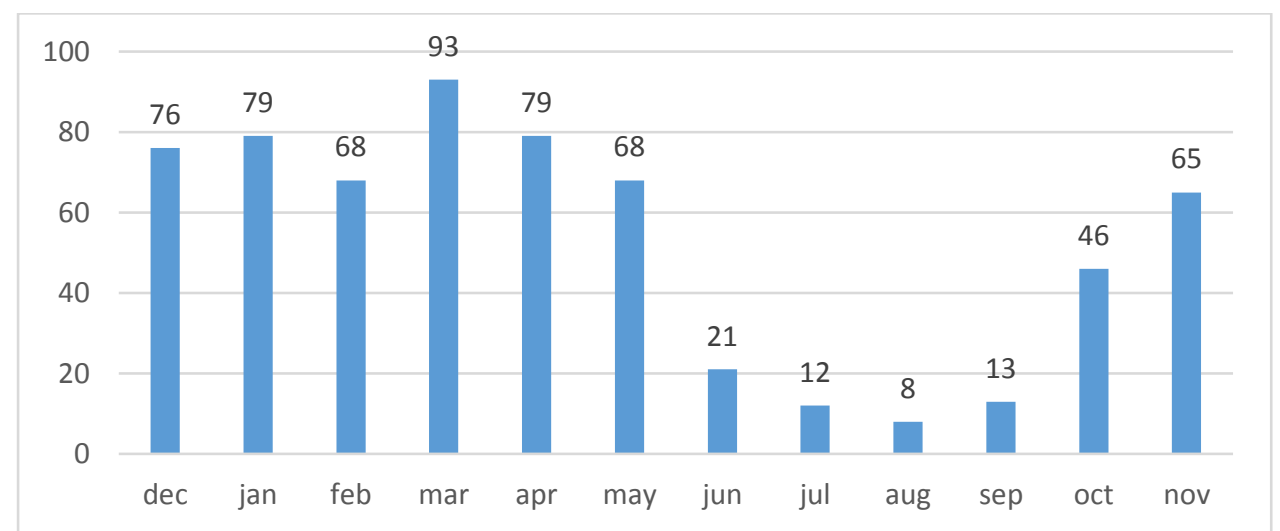

Figure 3. Monthly distribution of the COLs, which coincided with the rainfall in Iran or affected the rainfall in Iran 


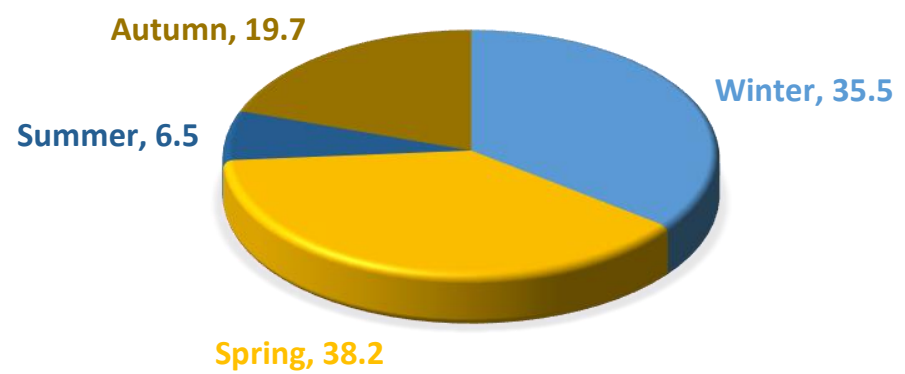

Figure 4. Seasonal distribution of the COLs, which coincided with the rainfall in Iran or affected the rainfall in

Iran

\section{- Annual distribution}

Figure 5 illustrates the annual frequency distribution of cut-off low systems affecting Iran during the study period (1976-2015). As can be seen in Figure 5, Iran has not been equally affected by these low pressures in different years. The frequency of occurrence has changed from 24 cases (1982) per year to nine cases (1976) per year. As mentioned, the highest frequency occurred in 1982 with 24 events and the second one in 2012 with 20 events. Also in these years, Iran has had one of the wettest years in its statistical period, which seems to be related to the occurrence of El Niño. Another noteworthy point is that the year coincides at least with the occurrence of La Niña. The trend line shows the occurrence trend of this phenomenon during the forty-year statistical period, which has a weak positive slope. This indicates that the frequency of cut-off low events during these years has had a weak, ascending slope.

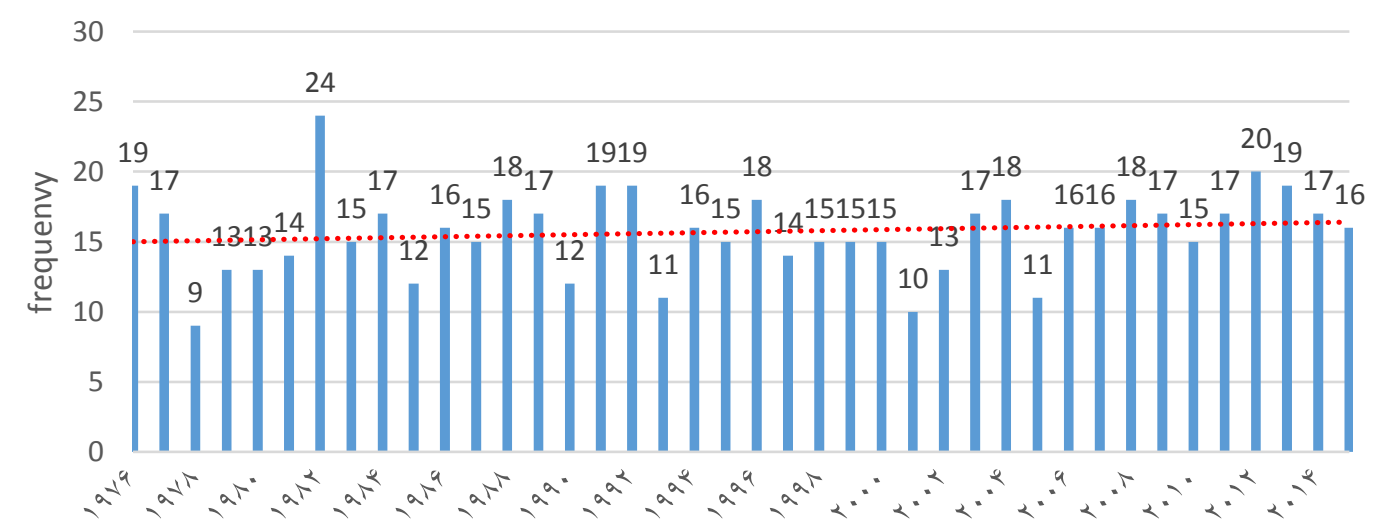

Figure 5. Annual frequency distribution of cut-off low systems affecting Iran during the study period (19762015). 


\section{- Duration}

In this research, cut-off lows with at least one-day persistency were taken into account. The longevity of cut-off lows affecting Iran was shown to be between 1 and 23 days. Figures 6 show the frequency distribution of cut-off lows with various duration affected Iran.

From the 628 identified cut-off lows, which affected Iran during the forty-year statistical period, cut-off lows with duration of two days were the most frequent, such that they constituted 107 events $(16.2 \%$ of total frequency). After that, three-day duration is the most frequent with $13.4 \%$. Four-day longevity with $12.8 \%$ and one-day longevity with $12.4 \%$ frequency are in the next ranks. Longevity of five days and above are sequentially and decreasingly in the next ranks, in regards of frequency percentage. Overall, $67 \%$ of cut-off lows have had a 1-5 day life span.

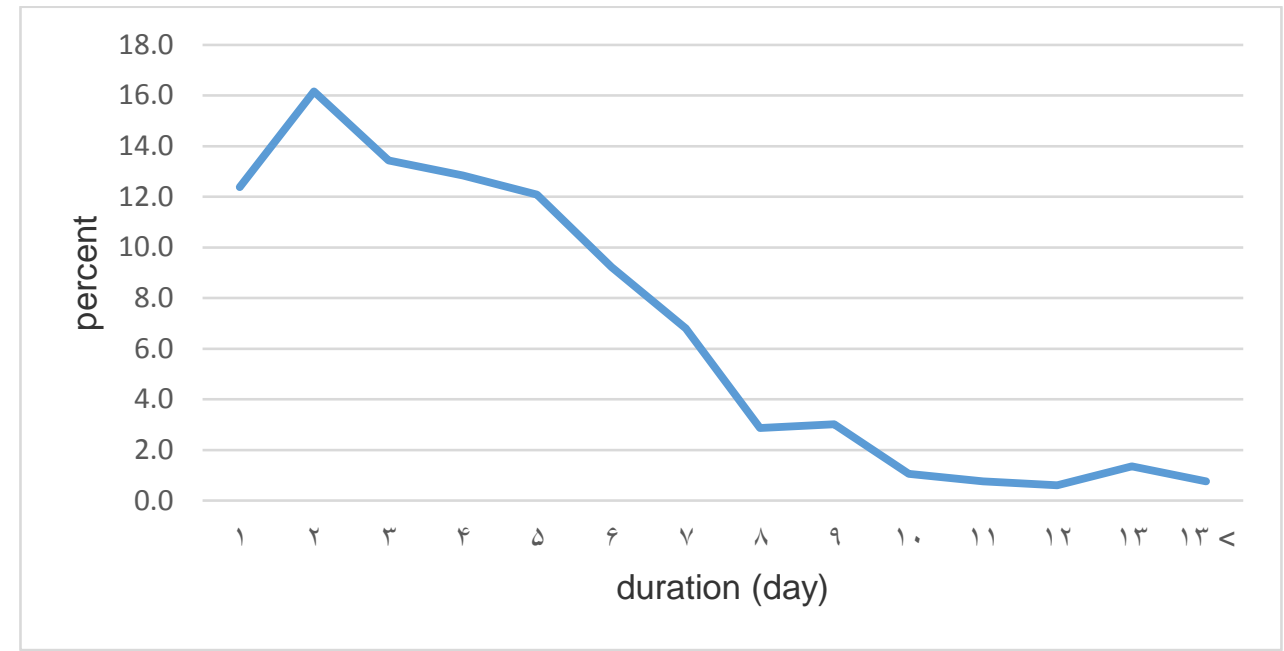

Figure 6. Percentage of COLs occurrence with different duration of 1 to 23 days during the statistical period (1976-2015)

\section{3- 3 Precipitation associated with COLS in Iran}

When moisture is available, COLs can lead to moderate or heavy rainfall over large areas (Knippertz and Martin, 2005). In order to study the effect of cut-off lows on precipitation in Iran, 23 synoptic stations were considered across the country. These stations were selected so that daily precipitation statistics during the fortyyear statistical period would be available, and their spatial distribution in Iran would cover most regions of the country as much as possible. Figure 7 shows the location of these stations throughout the country.

After identification of cut-off lows for the statistical period, their route and the days which these systems were present in Iran or effective on Iran were specified. On days, which were accompanied by cut-off low events, precipitation rate in stations affected by these systems (systems comprising one of the two conditions mentioned above) was obtained and the cumulative precipitation of all days, which were accompanied by cut-off lows for each station, was calculated for the statistical period. Afterwards, average forty-year precipitation of cut-off lows was calculated and compared with average annual precipitation of the station. Figure 8 shows the precipitation percentage associated with cut-off lows, as compared with total precipitation for each station. According to results, $28.3 \%$ of annual precipitation in Urmia is recharged by cut-off lows, which is the highest value among all studied stations. Other stations such as Saghez with about $25 \%$ and Zanjan with $24.5 \%$ are in the next ranks. The common denominator between these stations is being located in north-west of the country. Other stations that have experienced cut-off low associated precipitation of over $20 \%$ are Khorramabad (21.9 \%), Ahvaz (21.9\%), Tabriz (21.1\%), Rasht (20.9\%), Tehran (20.8\%), Kermanshah and Arak (about $20 \%)$. Moving from the north-west of the country to east and south, the rate of precipitation associated with these systems decreases. Babolsar station, for instance, receives a less portion of cut-off low associated precipitation compared to western stations, despite its high annual precipitation. The least percentage of Precipitation associated with COLs was also observed in the southeast quarter of the Iran as well. Therefore, stations such as Iranshahr and Bandar Abbas (8.2\%), Kerman (9.3\%), and Zahedan (9.5\%), which have the least precipitation 
associated with cut-off lows, are all located in this region of Iran. It is evident that Bandar Abbas has higher annual precipitation compared to stations such as Birjand in the Northeast or Isfahan in center of Iran, but has less share of the precipitation associated with COLs compared to these two cities, due to being located in the southeast region.

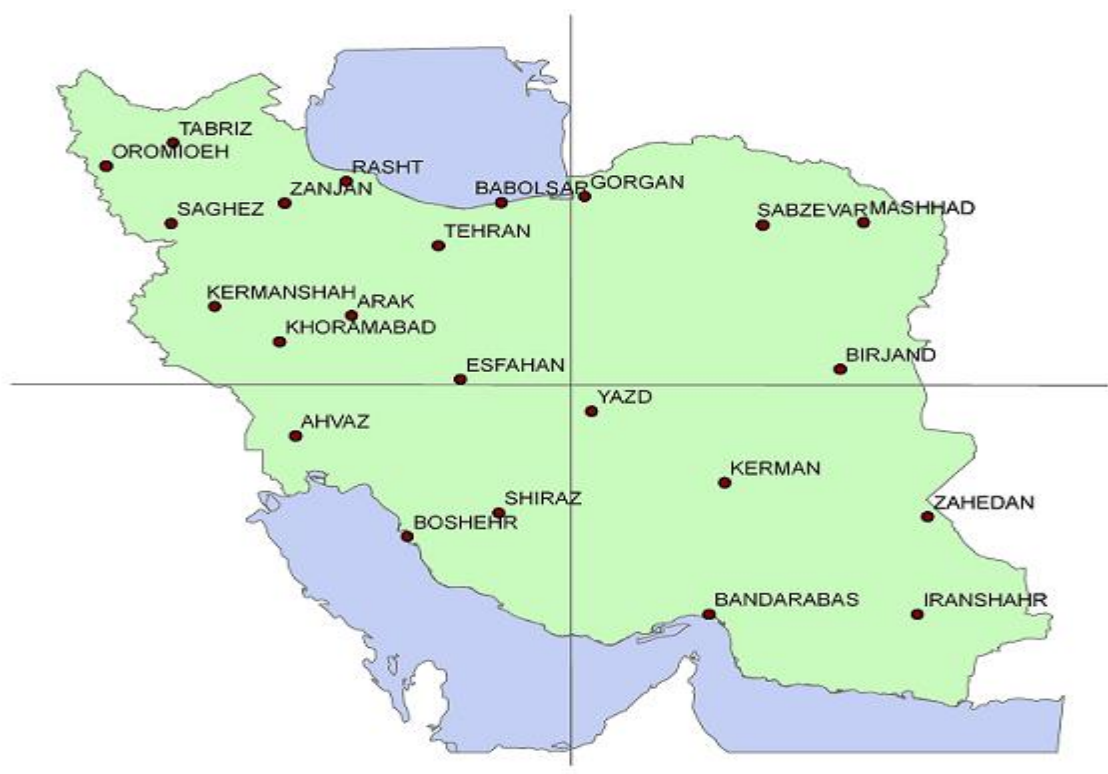

Figure 7. Geographical distribution of the selected meteorological stations

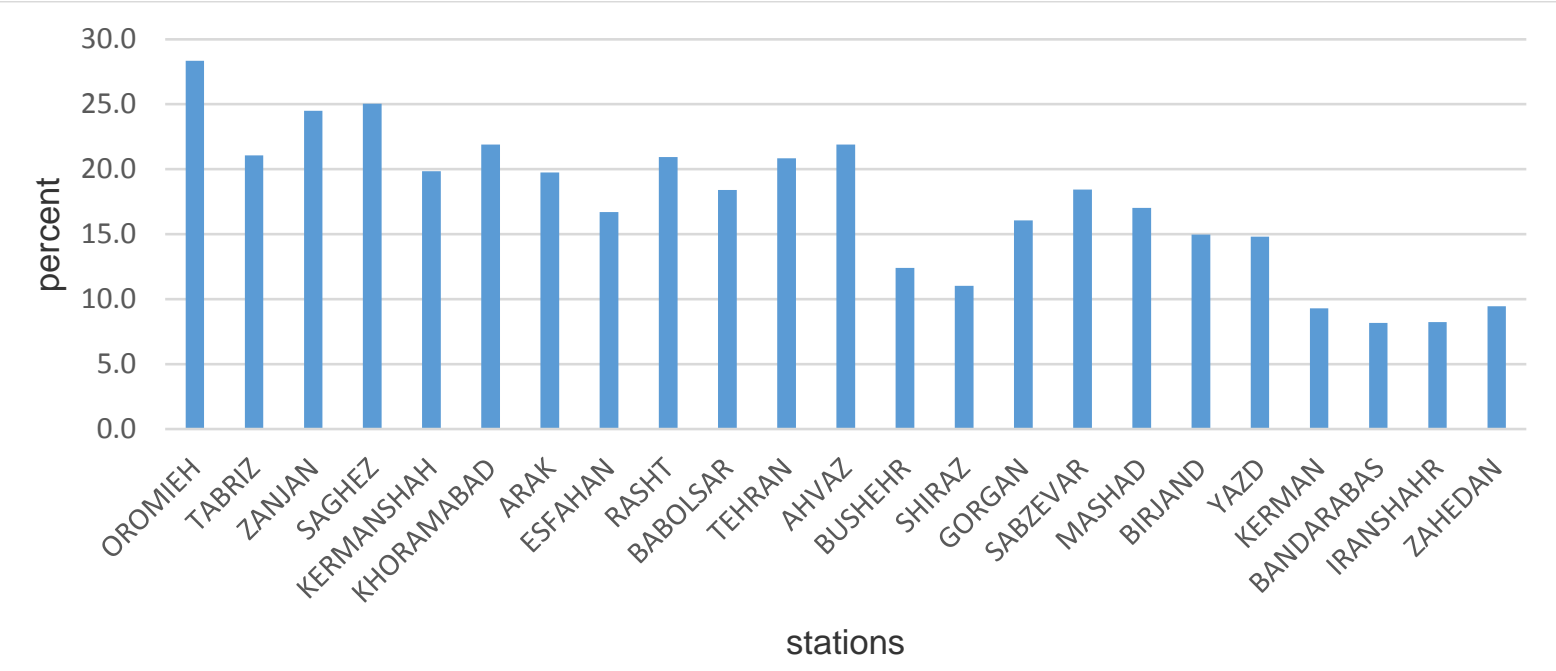

Figure 8 . The precipitation percentage associated with cut-off lows, as compared with total annual precipitation for each station.

\section{3- 4 Cut-off low patterns}

Cut-off lows are affected by the sinuosity of western winds to develop into various shapes and patterns, and are mostly influenced by blocking patterns. Association and affectability of cut-off low patterns with blocking systems are so high that their individual investigation is too hard. In fact, most cut-off low patterns are affected by blocking patterns and the formation of these systems is dependent on blocking highs. Following the traditional Rex (1950a) criterion, a blocking event can be identified through a split-flow regime in the middle 
troposphere as a double jet detectable over more than $45^{\circ}$ in longitude and persisting for more than 10 days (Barriopedro et al., 2006).

In this study, by visual investigation of daily weather maps during the statistical period, six pattern types of cutoff lows affecting Iran were identified which, will be reviewed below:

\section{- Eastern arm of Omega}

Omega $(\Omega)$ is one the most well-known forms of blocking. In this pattern, a very strong ridge advances to higher latitudes and there are two troughs or cut-off lows on sides. Each of its sections is accompanied by different weather conditions on the earth's surface, such that under the ridge and on the earth's surface, weather is clear, sunny, and warmer than usual, whereas at its lateral arms, due to establishment of a low altitude system, conditions on earth's surface are unstable and generally accompanied by precipitation. Blocking can affect precipitation systems due to its persistence, and increase their longevity more than usual as well as change their path by blocking the west to east route of eastern winds. At times where a cut-off low is formed at the right arm of the Omega pattern, the eastern arm of Omega pattern takes form (Figure 9: $\mathrm{L}_{2}$ ).

Centers of Omega block ridges affecting Iran are mostly located at latitudes of 40-65 degree north and in the center and east of Europe. However, considering that Iran is located east of the region of maximum block occurrence, it is affected mostly by cut-off lows on the right side of these blocks, which are largely of the Omega type. Hence, eastern arms of Omega blocks influencing Iran are developed in Europe. When Iran is positioned in front of the eastern arm of the Omega block, if other conditions exist, substantial and heavy precipitation will gradually be witnessed from the west. The cut-off low on the right side of Omega is accompanied by a low-pressure system on the earth's surface, and the deeper the cut-off low, the stronger the low-pressure system on the earth's surface will be, with longer life span and more powerful fronts, resulting in good continuous precipitation. Since the Omega block acts as a barrier, movement of the low-pressure system on the earth's surface decelerates, and the formation, strengthening and weakening of the front decelerates, leading to continuous precipitation. Generally, precipitation of the cut-off low patterns on the right side of Omega bear more intensity and persistence compared to the left side, and stronger low-pressure system is dominant on the earth's surface due to down flow of cold air from higher latitudes to the back part of the cut-off low. Given that in this pattern, air initially flows on the ridge of Omega and guides cold air to the eastern arm of Omega, this leads to strengthening of the cold front. Cut-off lows are deeper in strong blocks and atmospheric systems move to lower latitudes. Therefore, this pattern is influential even on the atmospheric systems' routes, and in the absence of the Omega pattern, most atmospheric systems move through more northern routes.

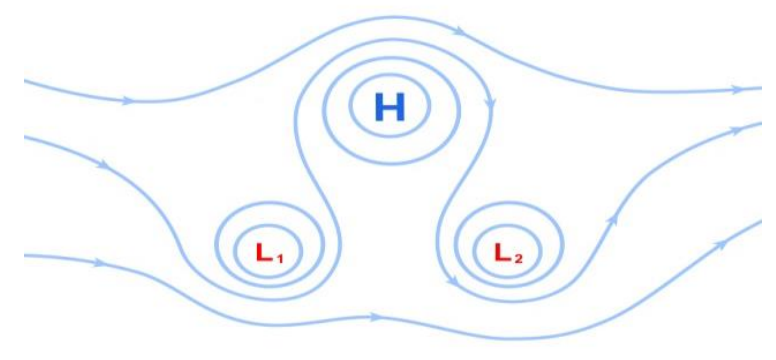

Figure 9. Schematic representation of omega East arm pattern (L2).

\section{- Western arm of Omega}

Anytime a cut-off low is developed in the left arm of the Omega block pattern, the western arm of Omega takes form (Figure 9: $\mathrm{L}_{1}$ ). When centers of Omega blocks are located at latitudes of 40-65 and longitudes of 50-70 degrees east, the cut-off low of their western arm affects Iran's weather. Although the frequency of this pattern is less than the previous pattern, but sometimes it affects Iran for a long time and for several days, and causes continuous precipitation in some regions. The western trough, in collision with the high and strong ridge of the Omega block, is bound to persistency and southward advancement, making it deeper and often transforming to a 
cut-off low. The western cut-off low of Omega is not always symmetrical to its eastern type and each may have different depths.

\section{- Inverted Omega}

In this pattern, which is shaped as a reversed Omega a deep trough between two ridges, is pulled to low latitudes forming a closed curve. In fact, the current is cut off and in this state, cold air flows to lower latitudes and becomes confined (Figure 10). Inverted Omega patterns with low altitude centers located at latitudes of 25-45 degrees north and longitudes of 30-60 degrees east are effective on Iran's weather.

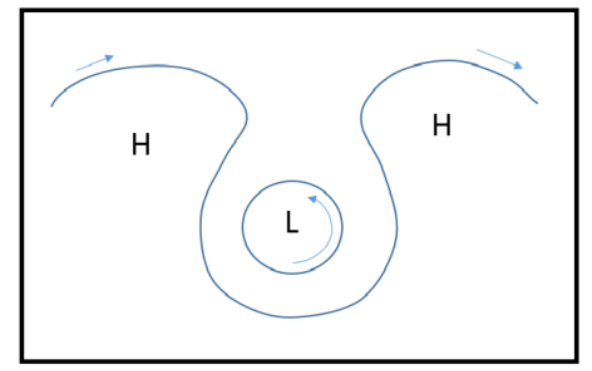

Figure 10. Schematic representation of the Inverted Omega pattern.

\section{- Rex pattern}

The Rex pattern is one of the most important blocking patterns, which identified in 1950 by Daniel F. Rex and named after him. Most often, this pattern is developed by the destruction of the western arm of Omega. In this pattern, a strong ridge is located in the north or north-west of a strong low-pressure region. In this system and in the path of the western winds, ridges are located first and then troughs, where flow initiates around the ridge and then moves around the trough such that air is taken through a curved path and in a longitudinal range, from high latitudes to low latitudes. Occurrence of this pattern leads to the development of cold and persistent air in high latitudes in the ridge zone, and warm and non-persistent air in low latitudes in the trough zone. The normal temperature gradient decreases, leading to slow eastward movement of the system. This pattern is shaped as a reverse S, and wind flow decelerates due to moving around this shape, which leads to its persistency in the region (Figure 11). A cut-off low usually develops in the southern trough of this pattern. When a ridge is developed on the tilted south-west/ north-east axis, sometimes a cut-off low develops in the southeast of it, resulting in the formation of a Rex pattern. Generally, when the ridge center of this pattern is developed in the latitudes of 40-65 degrees north and in the east of Europe, the cut-off low located in the southeast of it affects Iran.

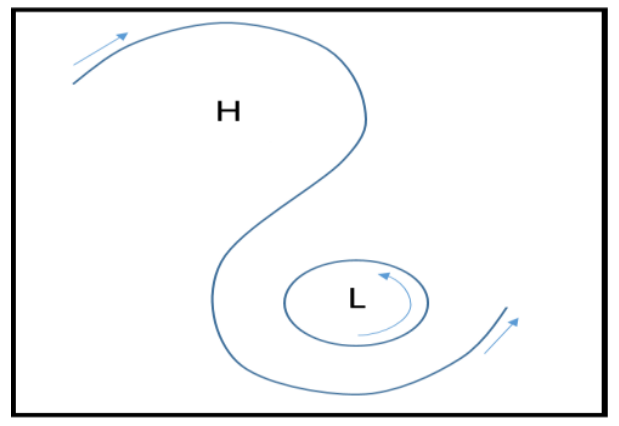

Figure 11. Schematic representation of the Rex pattern.

\section{- S pattern}


This pattern is often formed by destruction of the eastern arm of the Omega pattern. In this pattern, a ridge is located at the north or northeast of a trough. This pattern is the exact opposite of the Rex pattern, such that the western winds, following their path, first reach the trough, flow around it, and then encounter the ridge (Figure 12). In this pattern, the warmer air of latitudes lower than east of the trough moves around the ridge and flows to higher latitudes. This pattern resembles the letter S and cut-off lows usually develop in its southern trough. When a ridge is developed on the tilted north-west/ south-east axis, in some cases a cut-off low develops underneath it, resulting in the formation of an $\mathrm{S}$ pattern. Usually, when the ridge center is developed in the latitudes of 40-65 degrees north and longitude of 50-70 degrees east, the cut-off low located in the south-west of it affects Iran.

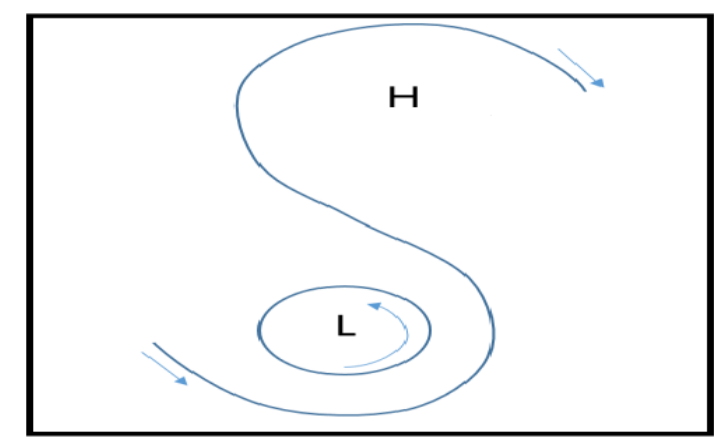

Figure 12. Schematic representation of the S Pattern.

\section{- Dipole pattern}

When a high altitude center is located north of a low altitude center, the dipole system develops. In this pattern, the main jet stream current is divided to two branches, one moves from its north side and the other from its south side (Figure 13). Systems reaching this region from the west side attenuate in the ridge and trough regions, but if they pass from in between these two branches, their movement slows down or relatively stops. This type of pattern is observed mostly on the western coasts of Europe and North America (Bluestein, 1993). Typically, in the dipole pattern, the low latitude southern system appears as a closed curve or a cut-off low. Anytime the region is under unstable circumstances caused by lower cut-off lows, conditions for instability and persistent precipitation are provided. In the dipole pattern, the high altitude center is located in higher latitudes, while the cut-off low is located in lower latitudes. The center of the $500 \mathrm{hPa}$ level low latitude is accompanied by a lowpressure system on the earth's surface. Cut-off lows located in the south of dipole patterns with their high altitude center located at latitudes of 40-65 degrees north and from east of Europe to Central Asia, influence Iran's weather.

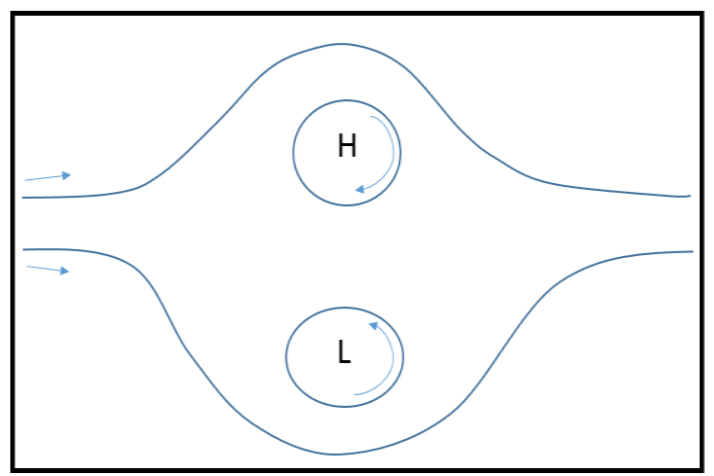

Figure 13. Schematic representation of the Dipole Pattern.

\section{3- 5 Annual distribution of patterns}


Figures 14 and 15 show the frequency and percentage of occurrence for various cut-off low patterns during the forty-year statistical period in Iran. It is evident that out of the 1436 days accompanied by cut-off low in Iran, the eastern arm of Omega pattern has the highest frequency with 374 days (26\%). The Inverted Omega pattern with 330 days $(23 \%)$ is in the next rank. After these two patterns, the Rex pattern with 296 days of cut-off low $(20.6 \%)$ ranks third, while the dipole patterns with 181 days (12.6\%), the S model with 135 days $(9.4 \%)$ and finally the western arm of Omega pattern with 120 days $(8.4 \%)$ are in further ranks.

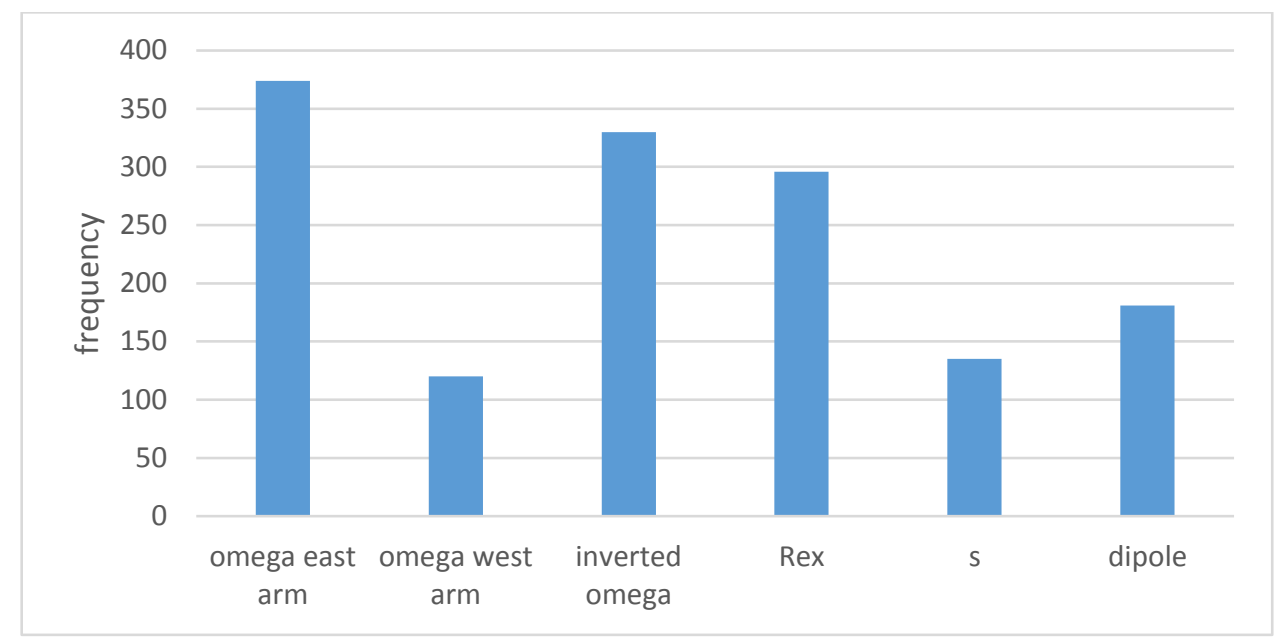

Figure 14. Long-term occurrence frequency of various cut-off lows that have affected Iran's rainfall.

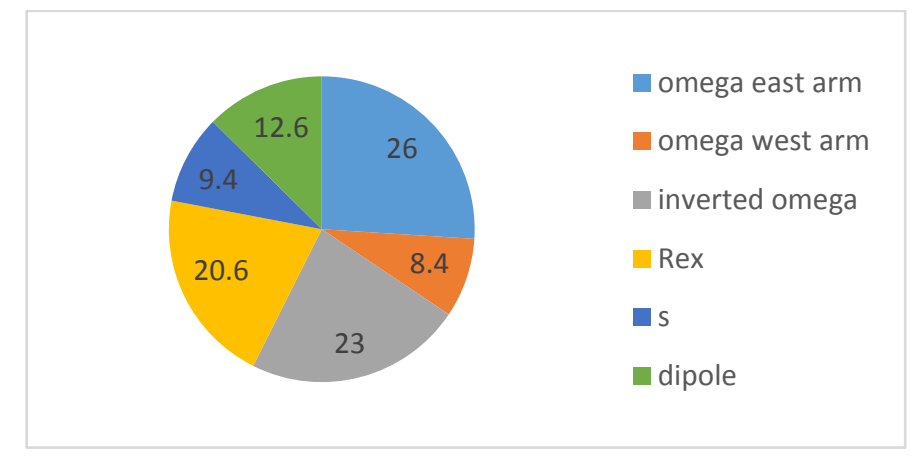

Figure 15. Percentage frequency of various cut-off lows patterns that have affected Iran's rainfall during the studied period.

\section{Conclusion}

During the forty-year statistical period, overall 628 cut-off lows affecting Iran with at least one day persistency were identified. The Geographical distribution of cut-off lows which coincided with the rainfall or affected the rainfall over Iran show that the generative zones affecting Iran are include a large areas, most of which are located east of the Mediterranean Sea and south of the Black Sea between $25^{\circ} \mathrm{E}-50^{\circ} \mathrm{E}$ and $32^{\circ} \mathrm{N}-38^{\circ} \mathrm{N}$.

In terms of monthly occurrence, because cut-off lows are part of the western winds and the western winds can expand to lower latitudes in the cold period of the year, the effect of these low pressures is mainly significant in the cold period of the year. Among the seasons, spring has the highest share with more than $38 \%$ (spring + winter about $74 \%$ ) and only about $8 \%$ of events are observed in summer. These results are consistent with the some studies that show the seasonal changes of cut-off lows are associated with jet stream, such that cut-off lows have more tendency to appear when jet streams are weak (Ndarana and Wag, 2010.(

These low pressures have not equally affected Iran in different years. The frequency of occurrence has changed from 24 cases (1982) per year to nine cases (1976) per year. It is noteworthy that the year with the maximum frequency coincides with the El Nino event and the year with the minimum occurrence coincides with the La Nino event. The trend in the frequency of cut-off lows over the last 40 years shows a weak positive trend. 
The lowest frequency for presence of cut-off lows effected Iran is that of summer which is the exact opposite of the European region and in general the higher latitudes of the northern hemisphere, since in these regions, the highest frequency of the COLs occurred in summer. The seasonal difference of these events in Iran compared to Europe and other regions located in higher latitudes is due to the constant presence of subtropical high pressure during the summer season in Iran, which does not grant entrance to westerlies systems.

From the 628 identified cut-off lows, events, which affected Iran during the forty-year statistical period, cutoff lows with duration of two days, were the most frequent, such that they constituted 107 events $(16.2 \%$ of total frequency). Overall, $67 \%$ of cut-off lows have had a 1-5 day life span.

Moving from the north-west of the country to east and south, the rate of precipitation associated with cut-off lows systems decreases. Just as different blocking patterns cause anomalies in Iran`s temperature (Azizi and khalili, 2011, Azizi et al, 2008, Azizi et al, 2015, Jafari et al., 2020) so also different blocking patterns cause the formation of various cut-off patterns and precipitation anomalies (Azizi and Khalili, 2013).

The frequency and percentage frequency of occurrence for various cut-off low patterns during the studied period made evident that out of the 1436 days accompanied by cut-off low in Iran, the eastern arm of the Omega pattern with 374 days has the highest frequency (26\%). Then The Inverted Omega pattern with 330 days (23\%) and the Rex pattern with 296 days (20.6\%), the dipole patterns with 181 days (12.6\%), the S model with 135 days $(9.4 \%)$, and finally the western arm of Omega pattern with 120 days $(8.4 \%)$ are in further ranks.

In Iran, late cold period and spring have the highest frequency of heavy precipitation related to blocking highs pattern, According to results, $67 \%$ of high intensities and $64 \%$ of normal cases of the precipitation coincides with Cut-off Lows, which belong to blocking highs patterns. According to studies on the temporal distribution of blocking highs affecting precipitation in Iran, the highest incidence of normal precipitation related to blocking highs occurred in winter (Azizi et al, 2012).

- Authors Contribution: "Both (All) authors have contributed equally to the work"

- Ethics approval: "The data used in this article were free"

- Consent to participate: 'Not applicable'

- Consent for publication: we give our consent for the publication of identifiable details of the manuscript in the Theoretical and Applied Climatology, which could be include tables, figure and other details.

\section{References}

- Azizi, Gh., Khalili, M. (2011). Roles of Blocking in Extreme Cold Events over Iran. Physical Geography Research Quarterly, 43(77), 39-55.

- Azizi G., Khalili M. (2013) An Investigation of Iran's Precipitation Anomalies in Relation with Atmospheric Blocking. In: Helmis C., Nastos P. (eds) Advances in Meteorology, Climatology and Atmospheric Physics. Springer Atmospheric Sciences. Springer, Berlin, Heidelberg. https://doi.org/10.1007/978-3-642-29172-2_74

- $\quad$ Azizi, Gh., T. Akbari, M. Davudi, et al., 2008: A synoptic analysis of January 2008 severe cold in Iran. Phys. Geogr. Res. Quart., 41, 316942.

- Azizi, Gh., M. Miri, and M. Rahimi, 2015: Identification of synoptic patterns influencing formation of temperature anomalies in Iran and Europe. Phys. Geogr. Res. Quart., 47, 91-104, doi: 10.22059/jphgr.2015.53680.

Azizi, G., Nabavy, S., Miri, M. (2012). Investigation of Blocking Pattern Role on Precipitation in North East of Iran Using Data Mining Analysis. Physical Geography Research Quarterly, 44(3), 109126. doi: 10.22059/jphgr.2012.29217

- Barriopedro, D., Garcı'a-Herrera, R., Lupo, A., Herna'ndez, E. (2006), Climatology of North Hemisphere blocking, J Climate.

- Bluestein, H. (1993), Synoptic-Dynamic Meteorology in Midlatitude, Observations and Theroy of Weather Systems, Oxford University Press, Volume II, pp. 594. 
- Chuanxi, L., YI, L., Liu, X., Chance, K. (2013), Dynamical and chemical features of a Cut-off Low over Northeast china in July 2007: Results from satellite Measurements and Reanalysis, Advances in Atmospheric Sciences, Volume 30, No. 2, PP 525-540.

- Delgado,G., Lorente., A. (2007), Cloud cover analysis associated to cut-off low pressure systems over Europe using Meteosat imaginery, Meteorol. Atmos. Phys. NO. 96, PP. 141-157.

- Favre, A., Hewitson, B., Tadross, M., Lennard, C., Mota, R. (2012), Relationships between cut-off lows and the semiannual and southern oscillations, Climate Dynamics, Volume 38, PP 1473-1487.

- Fuenzalida, H., Sanchez, R., Garreaud, R. (2005), A climatology of cut-off lows in the southern hemisphere, Journal of Geophysical Research, Volume 110, 1-10.

- $\quad$ Gimeno, L., Nieto, R. Trigo, R. (2007), Decay of the Northern Hemisphere stratospheric polar vortex and the occurrence of cut-off low systems: An exploratory study, Meteorology and Atmospheric physics, Volume 96, PP 21-28.

- Gouget, H., Vaughan, G., Marenco, A., Smit, H. (2000), Decay of a cut-off low and contribution to stratosphere-troposphere exchange, Q. J. R. Meteorol. Soc, Volume, PP1117-1141.

- Hodgson, Amy, 2012, Case study analysis of a cut-off low weather system over North-West Africa observed during the fennec pilot study, April 2011, Earth and Environment, volume 8, PP 38-105.

- Hoskins, B. J., McIntyre, M., Robertson, A. (1985), On the use and significance of isentropic potential vorticity maps, Quart. J. Roy. Meteor. Soc., NO. 111, PP. 877-946.

- Jafari Hombari, F., Barati, G. \& Moradi, M. (2020), Evaluation of the Relationship between Blocking Patterns and Duration of Spring Frost Waves: The Case of Iran. J Meteorol Res 34, 586-600 doi.org/10.1007/s13351-020-9140-8

- Kentarchos, A., Davies, T., (1998), A Climatology of cut-off lows at 200 hpa in the Northern Hemisphere 1990-1994, Intermational Journal Of Climatology, Volume 18, PP 379-390.

- Kleinschmidt E. (1950) Uber aufbau und entstehung von zyklonen I, Teil. Meteorologische Rundschau, NO. 3, PP. 1-7.

- Knippertz, P., Martin, J. (2005), Tropical plumes and extreme precipitation in subtropical and tropical West Africa. Q J Roy Meteor Soc.

- Ndarana, T., Waugh, D. (2010), The link between cut-off lows and Rossby wave breaking in the Southern Hemisphere, Quarterly Journal of the Royal Meteorological Society, Volume 136, PP 869885 .

- $\quad$ Nieto, R., Gimento, L., Torre, L., Ribera, P., Gallego, D., Herrera, R., Garcia, J., Nunez, M., Redano, A, Lorente, J. (2005), Climatological features of Cut-off Low Systems in the Northern Hemisphere, Journal of Climate, Volume 18, PP 3085-3103.

- $\quad$ Nieto, R., Gimeno, L., Anel, J., Torre, L., Gallengo, D., Barriopedro, D., Gallego, M., Gordillo, A., Redano, A., Delgado, G. (2007), Analysis of the precipitation and cloudiness associated with COLS occurrence in the Iberian Penensula, Meteorology and Atmospheric Physics, Volume 96, PP 103-119.

- $\quad$ Nieto, R., Gimeno, L., Torre, L., Ribera, P., Barriopedro, D., Herrera, R., Serrano, A., Gordillo, A., Redano, A., Lorente, J. (2007), Interannual varibility of cut-off low systems over the European sector: the role of blocking and the Northern Hemisphere circulation modes, Meteorology and Atmospheric Physics, Volume 96, PP 85-101.

- $\quad$ Nieto, R., Sprenger, M., Wernli, H., Trigo, R., Gimeno, L. (2008), Identification and Climatology of Cut-off Lows near the Tropopause, Trend And Directions In Climate Research, Volume 1146, PP 256290.

- $\quad$ Oakley, N., Redmond, K. (2014), A Climatology of 500-HPA closed lows in the Northeastern Pacific Ocean, 1948-2011, American Meteorological Socity, Volume 53, PP 1578-1592.

- Parker, S., Hawes, J., Colucci, S., Hayden, B. (1989), Climatology of $500 \mathrm{mb}$ cyclones and Anticyclones, 1950-85, American Meteorological Society, Volume 117, PP 558-570.

- Price, J.D. \& G. Vaughan. G. (1993), The potential for stratosphere-troposphere exchange in cut-off low systems, Quart. J. Roy. Meteor. Soc, NO. 119, PP. 343-365.

- Reboita, M., Nieto, R., Gimeno, L., Rocha, R., Ambrizzi, T., Garreaud, R., Kruger, L. (2010), Climatological features of cut-off low systems in the Southern Hemisphere, Journal of Geophysical Research, Volume 115, PP 1-15.

- $\quad$ Singleton, A., Reason, C. (2007), A Numerical model study of an intense cut-off low pressure system over south africa, Monthly weather review, volume 135, PP 1128-1150.

- Taljaard, J. (1985), Cut-off lows in the South African region, South African Weather Bureau Technical Paper, No. 14, pp153.

- Winkler, R. et al (2005), Manual of synoptic satellite meteorology. Conceptual models, Vers. 6.0. (Available at Central Institute for Meteorology and Geodynamics, Hohe Warte 38-1190 ViennaAustria). 